\title{
$\nabla$
}

\section{Infliximab in patients with psoriasis and other inflammatory diseases: evaluation of adverse events in the treatment of 168 patients}

\author{
João Roberto Antonio ${ }^{1,2}$ \\ Giovana Viotto Cagnon ${ }^{1}$ \\ Moacir Fernandes de Godoy ${ }^{1}$
}

\author{
Jessica Sanmiguel ${ }^{1}$ \\ Marília Silveira Faeda Augusto ${ }^{1}$ \\ Eurides Maria Oliveira Pozetti ${ }^{1}$
}

DOI: http:/ / dx.doi.org/10.1590/abd1806-4841.20164292

\begin{abstract}
BACKGROUND: Psoriasis is immune-mediated chronic inflammatory disease with preference for skin and joints. The skin involvement occurs by hyperproliferation and abnormal differentiation of keratinocytes. It is associated with comorbidities, mainly related to the clinical manifestations of the metabolic syndrome. Increased TNF-alpha expression (TNF- $\alpha$ ) is related to its pathophysiology. Infliximab is an intravenous drug that acts neutralizing the biological activity of TNF- $\alpha$ and prevents the binding of the molecule to the target cell receptor, inhibiting cell proliferation of psoriasis and other diseases mediated by TNF- $\alpha$. A lot of infusion reactions have been described in the literature.

ОвјестіvE: To evaluate the adverse effects of intravenous treatment with infliximab, analyzing patients with psoriasis compared to those with other chronic inflammatory diseases (rheumatoid arthritis, ankylosing spondylitis, Crohn's disease and ulcerative colitis).

METHOD: Analysis of medical records and adverse events of 168 patients undergoing infliximab infusion for psoriasis and chronic inflammatory diseases treatment.

RESULTS: 168 patients who have used infliximab were evaluated, 24 had psoriasis and 144 had chronic inflammatory diseases. Only $2(8.3 \%)$ patients with psoriasis showed adverse events requiring treatment discontinuation, and just $6(4.2 \%)$ female patients with chronic inflammatory diseases experienced adverse events.

CONCLUSION: Infliximab is a safe drug, with a low percentage of adverse events and there were more adverse events in women with chronic inflammatory diseases and in patients who received more infliximab infusions.

Keywords: Arthritis, rheumatoid; Crohn disease; Proctocolitis; Psoriasis. Spondylitis, ankylosing
\end{abstract}

\section{INTRODUCTION}

Psoriasis is a common skin disease in Brazil and in the world, affecting approximately $3 \%$ of the world population. It leads to a negative impact on patient's quality of life and is associated with decreased productivity, depression, alcoholism, smoking and increased prevalence of neoplastic disease. ${ }^{1,2}$

It is considered a chronic inflammatory disease with a predilection for skin and joints, with multifacto- rial etiology and genetic and environmental influence, which is characterized by involvement of the skin by hyperproliferation and abnormal differentiation of keratinocytes, and it is immunologically mediated (Th1). The disease is associated with comorbidities, especially those related to clinical manifestations of the metabolic syndrome, beyond spondyloarthropathies, uveitis and inflammatory bowel syndromes. ${ }^{1,3}$ 
An important factor related to the pathophysiological mechanism of the disease is the increased TNF- $\alpha$ expression, released by activated Th1 lymphocytes, as well as most chronic inflammatory diseases. Thus, drugs that act by inhibiting TNF- $\alpha$ have an important role in the treatment of these diseases. Among these drugs, infliximab has been highlighted. ${ }^{4}$

Infliximab acts neutralizing the biological activity of TNF- $\alpha$ by high affinity receptors with soluble and transmembrane TNF, forming an antigen-antibody complex that prevents binding of TNF- $\alpha$ molecule to the target cell receptor. As a result, the cell stops receiving proinflammatory stimulus and occurs the inhibition of cell proliferation, characteristic of psoriasis and other diseases mediated by TNF- $\alpha$, such as rheumatoid arthritis, Crohn's disease, ulcerative colitis and ankylosing spondylitis. ${ }^{5,6,7}$

The decision to use an anti-TNF- $\alpha$ agent must be individual, based on the specific clinical features and the specific patient risk profile. ${ }^{8}$

Treatment modalities for psoriasis are chosen according to disease severity, comorbidities, patient preference (including cost and convenience), effectiveness and individual assessment of response to treatment. Patients with moderate to severe psoriasis plaques should initially be treated with phototherapy and, in the presence of contraindications or failure, a systemic treatment agent should be indicated, such as infliximab. ${ }^{9}$

The contraindications to the use of infliximab should be considered, such as hypersensitivity to the drug, known by the patient, localized or systemic active infections, infection with human immunodeficiency virus, congestive heart failure with functional class III or IV according to the New York Heart Association, history of demyelinating disease, history of cancer (except when there was no recurrence in the last 5 years and in the case of patients with basal cell carcinoma) and history of systemic lupus erythematosus. Live attenuated vaccines should not be given during treatment. ${ }^{10}$ It is recommended updating vaccination before beginning a treatment with any anti-TNF- $\alpha$ agent. ${ }^{10}$

However, various infusion reactions have been described in the literature, and the occurrence in $3-22 \%$ have been reported in psoriasis patients treated with anti-TNF- $\alpha$ monoclonal versus $0-2 \%$ for placebo infusion. ${ }^{6,10,11}$

Adverse events can be divided into acute and late: A) Acute: occur during the infusion or until 24 hours after, such as flushing, chest tightness, nausea, dyspnea, headache, hypo/ hypertension, sweating, increased temperature and other symptoms of anaphylaxis, as urticaria and bronchospasm. ${ }^{10,12}$

B) Late: occur between 24 hours and 14 days after the infusion, and the main ones are arthralgia, my- algia, influenza-like symptoms, headache, fatigue, rash and urticaria.

In addition to these more common reactions, others have been reported and can occur during or after the infusion, such as induction and exacerbation of psoriasis, induction of pityriasis lichenoides chronica, formation of anti-DNA antibodies, lupus-like syndrome, malignancies, reactivation of tuberculosis primary focus, and alopecia. 1,3,9,13-17

With all this observations, we can see that the study of adverse events is of utmost importance for its greater understanding and a subsequent attempt to minimize or control them.

\section{OBJECTIVES}

To assess the prevalence of adverse events and their characteristics in patients receiving infliximab infusion at Hospital de Base de São José do Rio Preto, comparing psoriasis patients, with or without arthritis, to patients with other chronic inflammatory diseases subjected to treatment with this drug (rheumatoid arthritis, ankylosing spondylitis, Crohn's disease and ulcerative colitis), in order to observe the peculiarities of the adverse events of each group.

\section{METHODS}

This is a retrospective cross-sectional study. Data collection was performed through the analysis of medical records of 168 patients undergoing infliximab infusion for the treatment of psoriasis, with or without arthritis, and other chronic inflammatory diseases amenable to treatment with infliximab (rheumatoid arthritis, ankylosing spondylitis, Crohn's disease and ulcerative colitis), from the Dermatology and Rheumatology Service of Hospital de Base de São José do Rio Preto, 2005-2012.

Adverse events, as well as type of disease, sex, age and number of infliximab infusions, were collected and stored in an Excel spreadsheet and subjected to statistical analysis.

The nominal qualitative variables were compared with the help of the Chi-square test and Fisher's exact test. The continuous quantitative variables with Gaussian distribution were analyzed with the help of the unpaired $t$ test. In the case of quantitative variables without Gaussian distribution, we used the nonparametric Mann-Whitney test. All tests were applied with the assistance of the program StatsDirect Statistical Software 1.9.15.

An alpha error of 5\% was admitted, being considered significant values of $\mathrm{p} \leq 0.050$.

The study was approved by the Ethics Committee of the FAMERP of São José do Rio Preto-SP under the number CAAE 16186513.2.0000.5415. 


\section{RESULTS}

Of the 168 patients evaluated using infliximab, 24 had psoriasis, 2 of them had arthritis associated with skin lesion and 144 had chronic inflammatory diseases amenable to treatment with infliximab (rheumatoid arthritis, ankylosing spondylitis, Crohn's disease and ulcerative colitis).

Of psoriasis patients, only $2(8.3 \%)$ presented adverse events requiring discontinuation of treatment. One of them had lupus-like reaction and the other patient had an anaphylactic reaction.

Of the patients with chronic inflammatory diseases (CID), 6 (4.2\%) experienced adverse events, which are: lupus-like reaction $(2 ; 33.3 \%)$, hyperemia $(1 ; 16.6 \%)$, papular rash $(2 ; 33.3 \%)$ and anaphylactic reaction $(1 ; 16.6 \%)$. In all cases, the suspension of the treatment was needed (Table 1$)$.

Regarding gender, $75(44.4 \%)$ patients were men, of these $1(1.3 \%)$ showed adverse events, and $93(55.6 \%)$ were women, of these, 7 (7.5\%) presented adverse events. Of psoriasis patients, with or without arthritis, 13 (54.2\%) were women and 11 (45.8\%) were men, and 1 patient in each group presented adverse events (7.6\% of women and $9.0 \%$ of men). In the group of patients with other chronic inflammatory diseases, 64 were men $(44.4 \%)$ and $80(55.6 \%)$ were women, with $100 \%$ of the reactions occurring among female patients (6) (Table 2).

There was no statistically significant difference in gender or age when comparing the groups of diseases (psoriasis versus chronic inflammatory diseases) (Table 2).

The comparative analysis using Fisher's exact test showed that there is no significant difference in the frequency of adverse events between chronic inflammatory diseases and psoriasis $(p=0.408)$.

The analysis in each group (with psoriasis and chronic inflammatory disease) in terms of relation of age with frequency of adverse events showed no

TABle 1: Characteristics of adverse events of patients, São José do Rio Preto, Brazil, 2015

\begin{tabular}{llllc}
\hline Indication & Gender & $\begin{array}{l}\text { Age } \\
\text { (years) }\end{array}$ & $\begin{array}{l}\text { Type of } \\
\text { event }\end{array}$ & $\begin{array}{c}\text { Number of } \\
\text { infusions }\end{array}$ \\
\hline CID & F & 18 & Anaphylaxis & 15 \\
CID & F & 59 & Hyperemia & 18 \\
CID & F & 41 & Lupus-like & 4 \\
CID & F & 54 & Lupus-like & 6 \\
CID & F & 60 & Papular eruptions & 35 \\
CID & F & 46 & Papular eruptions & 10 \\
PSORIASIS & F & 56 & Lupus-like & 3 \\
PSORIASIS & M & 60 & Anaphylaxis & 3 \\
\hline
\end{tabular}

$\mathrm{CID}=$ Chronic Inflammatory Diseases studied. $\mathrm{M}=$ male $\mathrm{F}=$ female statistically significant differences by unpaired $t$ test ( $p=0.379$ for patients with chronic inflammatory diseases and $p=0.342$ for patients with psoriasis).

A comparative analysis for each group in terms of relation between gender with frequency of adverse events using the Fisher test showed that there was clinical significance only in the group of inflammatory bowel disease $(p=0.050)$, demonstrating a higher incidence of adverse events in women, but presenting no evidence of clinical significance when performed comparative analysis in psoriasis group $(\mathrm{p}=0.199)$.

Regarding the dose, using the nonparametric Mann-Whitney test, it was demonstrated that there is no relation between it and the frequency of adverse events $(p=0.368)$.

As for the number of infusions, comparing the group with adverse events to the one without them, from the non-parametric Mann-Whitney test it was showed that the group presenting adverse events was subjected to more infusions than the other group $(p=0.020)$ (Figure 1), with a median of 8 infusions in the group without adverse events and 21 infusions in the group with adverse events.

TABle 2: Demographic data of the sample, São José do Rio Preto, Brazil, 2015

\begin{tabular}{llll}
\hline & Psoriasis & CID & P-value \\
\hline Sample & 24 & 144 & \\
M (\%) & $11(45.8)$ & $64(44.4)$ & \\
& & & $>0.999^{*}$ \\
F (\%) & $13(54.2)$ & $80(55.6)$ & \\
Adverse events N (\%) & $2(8.3)$ & $6(4.2)$ & $0.408^{* *}$ \\
Mean age (anos) & $47.7 \pm 15.7$ & $46.6 \pm 13.9$ & $0.738^{* * *}$ \\
\hline
\end{tabular}

* Chi-square test ${ }^{* *}$ Fisher exact test ${ }^{* * *}$ Unpaired t-test $\mathrm{M}=$ male $\mathrm{F}=$ female

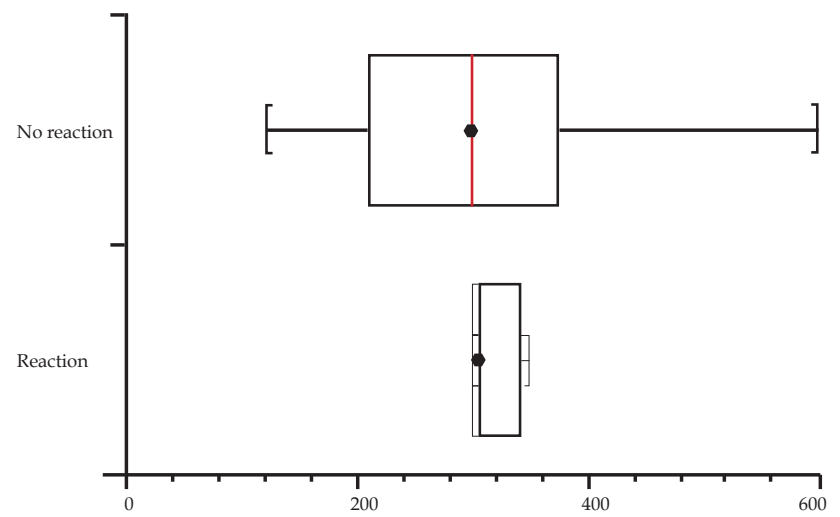

Figure 1: Number of infusions in the group with no adverse events (G2) in relation to the number in the group with reactions (G1). Minimum $<$ [lower quartile - median- superior quartile]> Maximum, São José do Rio Preto, Brazil, 2015 
Regarding the frequency of infusions, among the 8 patients that presented adverse events, $75.0 \%$ (6) had delay between infusions. Statistical analysis of this data was hampered by lack of sufficient data for analysis of the total sample records.

\section{DISCUSSION}

Several studies demonstrate the infusion reactions resulting from infliximab administration in the treatment of both psoriasis and other chronic inflammatory diseases, justifying the importance of the study and prevention of such reactions.

Studies also show that the occurrence of infusion reactions in psoriasis patients treated with anti-TNF- $\alpha$ monoclonal is $3-22 \% .^{10}$ We observed in this study an occurrence of infusion reactions of $8.3 \%$ in psoriasis patients undergoing this treatment.

Symptoms described in the literature, such as arthralgia, myalgia, influenza-like symptoms, headache, fatigue, induction and exacerbation of psoriasis, induction of pityriasis lichenoides chronica, formation of anti-DNA antibodies or reactivation of tuberculosis primary focus, wasn't observed in the results presented here. $13,10,12,13,14,17$ The main infusion reaction observed in this retrospective study was lupus-like symptoms, accounting for $37.5 \%$ of the adverse events found, and this reaction has already been demonstrated in numerous studies.

The profile of infusion reactions of patients studied here does not include some reactions already described, such as the correlation between treatment with infliximab and the development of malignancies, or cases of palmoplantar pustulosis ${ }^{4}$ induced by treatment with the monoclonal antibody in patients with psoriasis or other chronic inflammatory diseases. There were also no reports of exacerbation of clinical findings after treatment or induction of pityriasis lichenoides chronica. ${ }^{13,14,16}$

There are reports in the literature of a type of adverse event called serum sickness-like, a type of hypersensitivity reaction, resulting from deposit in the tissues of circulating antigen-antibody complex formed after the infusion of the drug. ${ }^{12}$ The clinical manifestations of this setting are rash, fever and polyarthralgia or polyarthritis, beginning after 1 to 2 weeks of the infusion. There were no reports of such reactions in patients analyzed in this study.

It was observed in the study a greater number of adverse events in women who presented chronic inflammatory diseases, and $100 \%$ of patients experiencing adverse events in this group were female. Recent studies on the influence of gender on the frequency of adverse events are scarce and controversial. However, some studies corroborate the data, showing more reactions in women and highlighting the female gender as a risk factor for infusion reactions. ${ }^{18,19}$

We also found as a predictor of infusion reactions the number of infusions $(\mathrm{p}=0.020)$. This finding contradicts recent studies that observed more infusion reactions during the first infusion of the medication, showing a drop in the frequency of reactions according to the increase of the number of infusions in patients. ${ }^{20,21}$

We can consider as a bias of this study the absence of sufficient data to conduct comparative analysis between delayed infusions and frequency of adverse events. It is known that a long interval between infusions is a risk factor for infusion reactions, and long periods without treatment result in higher incidences of serious infusion reactions. ${ }^{22,23}$

\section{CONCLUSION}

It can be concluded that infliximab is a safe drug, with a low percentage of adverse events, but with peculiarities in relation to the studied parameters. We demonstrated the presence of a higher percentage of adverse events in women with inflammatory bowel diseases amenable to treatment with infliximab, but there is no clinical significance in comparative analysis between gender and frequency of reactions in psoriasis group. It is also observed in the study, a higher frequency of adverse events in patients who underwent a greater number of infusions.

More studies are necessary to corroborate previous findings on the subject.] 


\section{REFERENCES}

1. Duarte AA, Pinto JM. Artrite Psoriásica e comorbidades. In: Sociedade Brasileira de Dermatologia. Consenso Brasileiro de Psoríase 2009. Rio de Janeiro: Sociedade Brasileira de Dermatologia; 2009. p.31-6.

2. Patel RV, Clark LN, Lebwohl M, Weinberg JM. Treatments for psoriasis and the risk of malignancy. J Am Acad Dermatol. 2009;60:1001-17.

3. Chan CY, Browning JC, Larsen F, Hsu S. Development of new-onset psoriasis in a patient receiving infliximab for treatment of rheumatoid arthritis. Dermatol Online J. 2008;14:12

4. Mössner R1, Thaci D, Mohr J, Pätzold S, Bertsch HP, Krüger U, et al. Manifestation of palmoplantarpustulosis during or after infliximab therapy for plaque-type psoriasis: report on five cases. Arch Dermatol Res. 2008;300:101-5.

5. Valdés A Mdel P, Schroeder H F, Roizen G V, Honeyman M J, Sánchez M L. Efficacy of infliximab in patients with moderate and severe psoriasis treated with infliximab (Remicade). Rev Med Chil. 2006;134:326-31.

6. Reich K, Nestle FO, Papp K, Ortonne JP, Evans R, Guzzo C, et al. Infliximab indution and maintenance therapy for moderate-to-severe psoriasis: a phase III, multicentre, double-blind trial. Lancet. 2005;366:1367-74.

7. Kleyn CE, Griffiths CE. Infliximab for treatment of psoriasis. Expert Opin Biol Ther. 2006;6:797-805

8. Uptodate.com [Internet]. John H S. Tumor necrosis factor-alpha inhibitors: An overview of adverse effects. UpToDate. 2014. [cited 2015 mar 01]. Available from: http://www.uptodate.com/contents/tumor-necrosis-factor-alpha-inhibitorsan-overview-of-adverse-effects.

9. Uptodate.com [Internet]. John H S. Tumor necrosis factor-alpha inhibitors: Risk of bacterial, viral, and fungal infections. UpToDate. 2014 [cited 2015 mar 01]. Available from: http://www.uptodate.com/contents/tumor-necrosis-factor-alphainhibitors-risk-of-bacterial-viral-and-fungal-infections.

10. Lecluse LL, Piskin G, Mekkes JR, Bos JD, de Rie MA. Review and expert opinion on prevention and treatment of infliximab-related infusion reactions. $\mathrm{Br} J$ Dermatol. 2008;159:527-36.

11. Gottlieb AB, Evans R, Li S, Dooley LT, Guzzo CA, Baker D, et al Infliximabeinditiontherapy for pacients with severe plaque types psoriasis: a randomized doubleblind, placebo-controlled trial. J Am Acad Dermatol. 2004;51:534-42.

12. Cheifetz A, Mayer L. Monoclonal antibodies, immunogenicity, and associated infusion reactions. Mt Sinai J Med. 2005;72:250-6.

13. Ko JM, Gottlieb AB, Kerbleski JF. Induction and exacerbation of psoriasis with TNFblockade therapy: a review and analysis of 127 cases. J Dermatolog Treat. 2009;20:100-8

14. Newell EL, Jain S, Stephens C, Martland G. Infliximab-induced pityriasislichenoideschronica in a patient with psoriasis. J Eur Acad Dermatol Venereol. 2009;23:230-1.

15. Benucci M, Nenci G, Cappelletti C, Manfredi M. Lupus like syndrome induced by treatment with anti TNFalpha (infliximab): report of three cases. Recenti Prog Med 2008;99:363-6.

16. Chaudhari U, Romano P, Mulcahy LD, Dooley LT, Baker DG, Gottlieb AB. Efficacy and safety of infliximab monotherapy for plaque-type psoriasis: a randomised trial. Lancet. 2001;357:1842-7.
17. Doherty SD, Van Voorhees A, Lebwohl MG, Korman NJ, Young MS, Hsu S, et al. National Psoriasis Foundation consensus statement on screening for latent tuberculosis infection in patients with psoriasis treated with systemic and biologic agents. J Am Acad Dermatol. 2008;59:209-17.

18. Crandall WV, Mackner LM. Infusion reactions to infliximab in children and adolescents: frequency, autcome and a predictive model. Aliment Pharmacol Ther. 2003;17:75-84.

19. Han PD, Cohen RD, Motamedi F, Hanauer SB. Infliximab infusion reactions. The influence of sex and drugs. Gastroenterology 2002:122:A612

20. Colombel JF, Sandborn WJ, Reinisch W, Mantzaris GJ, Kornbluth A, Rachmilewitz D, et al. Infliximab, azathioprine, or combination therapy for Crohn's disease. N Engl J Med. 2010;362:1383-95.

21. Janssen-Cilag.com.br [Internet]. Janssen-cilag. Bula REMICADE ${ }^{\circledR}$ (infliximabe).2015 [cited 2015 mar 01]. Available from: http://www.janssen-Cilag. com.br/sites/default/files/REMICADE_PUBV02_VPS.pdf.pdf.

22. Cullen G, Cheifetz AS. Infusion reactions related to Infliximab therapy are not usually associated with drug discontinuation. J Rheumatol. 2012;39:1500-2.

23. Kelsall J, Rogers P, Galindo G, De Vera MA. Safety of infliximab tratment in patients with rheumatoid arthritis in a real-wold clinical setting: Description and evaluation of infusion reactions. J Rheumatol. 2012;39:1539-45.

MAILING ADDRESS:

João Roberto Antonio

R. Silva Jardim, 3114

Centro

15010-060 - São José do Rio Preto - SP

Brazil

Email:dr.joao@terra.com.br

How to cite this article: Antonio JR, Sanmiguel J, Cagnon GV, Augusto MSF, Godoy MF, Pozetti EMO. Infliximab in patients with psoriasis and other inflammatory diseases: evaluation of adverse effects in the treatment of 168 patients. An Bras Dermatol. 2016;91(3):306-10. 